\title{
SOME INEQUALITIES CONSTRUCTED BY TCHEBYSHEFF'S INTEGRAL INEQUALITY
}

\author{
Feng Qi, Li-Hong Cui AND SEN-Lin Xu
}

\begin{abstract}
In the article, using Tchebysheff's integral inequality, the authors refine Conte's inequality and some estimates concerning the probability integral which are related to the Mills' ratio, form several inequalities of trigonometric functions, obtain some integral inequalities and estimates of definite integrals related to $\sin x / x, x \in[0, \pi / 2]$, and construct many miscellaneous inequalities.
\end{abstract}

Mathematics subject classification (1991): Primary 26D15; Secondary 33B20, 60E15.

Key words and phrases: Probability integral, Conte's inequality, Jordan's inequality, Fejér-Jackson's inequality, Tchebysheff's integral inequality, trigonometric function, integral inequality, Wallis' inequality.

\section{REFERENCES}

[1] U. ABEL AND D. CACCIA, A sharpening of Jordan's inequality, Amer. Math. Monthly 93 (1986), no. 7, 568.

[2] J. T. CHU, On bounds for the normal integral, Biometrika 42 (1955), 263-265.

[3] J. M. CONTE, Solution of problem 5607, Revue Math. Spec. 74 (1963/64), 227-230.

[4] G. H. Hardy, J. E. LitTlewoOd AND G. PólYa, Inequalities, 2nd edition, Cambridge University Press, 1952.

[5] A. A. Krishnaswami Ayyangar, Problem 1800, Math. Student 11 (1943), 63.

[6] G. Klambauer, Mathematical Analysis, Chinese Edition, The People's Press of Hunan, Changsha, China, 1981. (Translated by Ben-Wang Sun)

[7] Ji-Chang Kuang, Applied Inequalities, 2nd edition, Hunan Education Press, Changsha, China, 1993. (Chinese)

[8] D. S. Mitrinović, Problem 5555, Amer. Math. Monthly 75 (1968), 84 and 1129-1130.

[9] D. S. Mitrinović, Analytic Inequalities, Springer-Verlag, Berlin, 1970.

[10] D. S. Mitrinović, J. E. PeČARIĆ AND A. M. Fink, Classical and New Inequalities in Analysis, Kluwer Academic Publishers, Dordrecht/Boston/London, 1993.

[11] A. OstowsKI, Vorlesungen über Differential-und Integralrechnung, Vol. 3, Basel-Stuttgart, 1954.

[12] FENG QI, Proofs for a class of integral inequalities and their applications, In "Collected Papers of the First Youth Academic Annual Meeting of Henan Province", 91-93, Press of Science and Technology of China, Beijing, China, 1995. (Chinese)

[13] Feng QI, Generalized weighted mean values with two parameters, Proc. Roy. Soc. London Ser. A 454 (1998), no. 1978, 2723-2732.

[14] FEnG QI, On a two-parameter family of nonhomogeneous mean values, Tamkang Journal of Mathematics 29 (1998), no. 2, 155-163.

[15] FEnG QI, Monotonicity results and inequalities for the gamma and incomplete gamma functions, submitted for publication.

[16] FENG QI AND BAI-Ni GUO, Lower bound of the first eigenvalue for the Laplace operator on compact Riemannian manifold, Chinese Quarterly Journal of Mathematics, 8 (1993), no. 2, 40-49.

[17] FENG QI AND SEN-LIN GUO, Inequalities for the incomplete gamma and related functions, Math. Ineq. Appl. 2 (1999), no. 1, 47-53. 
[18] FEnG QI AND QIN-DAO HaO, Refinements and sharpenings of Jordan's and Kober's inequality, Mathematics and Informatics Quarterly 8 (1998), no. 3, 116-120.

[19] Feng Qi AND Zheng HuAng, Inequalities of the complete elliptic integrals, Tamkang Journal of Mathematics 29 (1998), no. 3, 165-169.

[20] Feng QI AND JiA-QIANG MeI, Some inequalities of the incomplete gamma and related functions, Zeitschrift für Analysis und ihre Anwendungen 18 (1999), no.3, 793-799.

[21] Feng QI AND SEN-Lin Xu, The function $\left(b^{x}-a^{x}\right) / x$ : Inequalities and properties, Proc. Amer. Math. Soc. 126 (1998), no. 11, 3355-3359.

[22] FEng QI AND SEN-Lin Xu, Refinements and extensions of an inequality, II, J. Math. Anal. Appl. 211 (1997), 616-620.

[23] Feng Qi AND ShI-QIn Zhang, Note on monotonicity of generalized weighted mean values, Proc. Roy. Soc. London Ser. A 455 (1999), no. 1989, 3259-3260. 